\title{
Observaciones, desafíos y oportunidades en el manejo de efluentes de feedlot en la provincia de Buenos Aires, Argentina
}

\author{
ana R. García ${ }^{\varpi ;}$ Santiago N. Fleite; Ileana Ciapparelli; Daniela Vázquez Pugliese; \\ Cristian Weigandt \& Alicia Fabrizio de Iorio
}

Cátedra de Química Analítica, Facultad de Agronomía, Universidad de Buenos Aires

\begin{abstract}
Resumen. La acumulación de estiércol de ganado vacuno sobre la superficie de los corrales en actividades de engorde a corral o feedlot genera grandes volúmenes de efluentes que pueden afectar la calidad del agua superficial y subsuperficial. El objetivo de este trabajo es examinar y sintetizar información disponible sobre aspectos involucrados en el manejo actual de los efluentes de feedlots en la provincia de Buenos Aires, destacando los efectos ambientales y poniendo en evidencia debilidades y futuras acciones que se podrían implementar. Se describen los efectos de esta actividad sobre la calidad de los cuerpos de agua y se analizan las reglamentaciones vigentes, haciendo especial referencia a los criterios y/o a los niveles de vertido propuestos en ellas. Este análisis pone en evidencia ciertos vacíos e incongruencias, así como también la necesidad y oportunidad de ajustar y ampliar las reglamentaciones. Por último, se propone un esquema operativo utilizado para enmarcar el análisis de diferentes aspectos involucrados en el manejo de los efluentes de los feedlots. El esquema identifica cuatro componentes definidos a partir de la elaboración de un Plan de Manejo de Nutrientes $(\mathrm{PMN})$ y de la determinación de un Criterio de Control de Efluentes (CCE).
\end{abstract}

[Palabras clave: residuos de feedlot, contaminación del agua, regulaciones, estrategias de manejo]

\begin{abstract}
Aвstract. Observations, challenges and opportunities in feedlot effluents management in Buenos Aires Province, Argentina: The accumulation of beef cattle manure on feedlot pen surfaces generates large effluent volumes which can impact surface and groundwater quality. The aim of this study is to examine and summarize the available information on feedlot effluents management in Buenos Aires Province, highlighting the environmental effects and the weaknesses and future actions suitable to be implemented. We describe the environmental effects of this activity over waterbodies quality and analyze the existing regulations, with special emphasis on criteria and / or discharge levels proposed by legislation. This study reveals some gaps and incongruence as well as needs and opportunities for adjustment and expanding of existing regulations. Finally, an operating scheme used to frame the analysis of different aspects involved in feedlot effluent management is proposed. Such scheme identifies four components defined considering the development of a Nutrient Management Plan (NMP) and the determination of an Effluent Control Criterion (ECC).
\end{abstract}

[Keywords: feedlot wastes, water pollution, regulations, management strategies]

\section{INTRODUCCIÓN}

En Argentina, la expansión de la agricultura ha desplazado la producción de bovinos para carne sobre pasturas implantadas o vegetación natural hacia áreas marginales de menor productividad. Al mismo tiempo, la demanda de productos cárnicos requirió mantener la producción mediante nuevas estrategias productivas como el engorde a corral (feedlot). Es así como la actividad creció en la última década y se instaló en diversas regiones del país, en particular en la pampa húmeda, que a junio de 2013 concentraba $80 \%$ de los feedlots declarados (SENASA 2013). Estos establecimientos acompañan a las grandes plantas de faena y a los centros urbanos de consumo como una forma de disminuir costos. Consisten en mantener a los animales dentro

Editora asociada: María Semmartin

\section{$\triangle$ agarcia@agro.uba.ar}

de corrales desprovistos de cobertura vegetal, con una dieta de valor energético elevado y alta digestibilidad (alimentos concentrados). El elevado número de cabezas por unidad de superficie implica la acumulación de estiércol (mezcla de heces y orina) sobre el piso o el suelo de los corrales de engorde, que puede ser movilizado por procesos de escorrentía superficial, alcanzar cuerpos de agua y degradar su calidad.

De acuerdo con los informes provistos por el Servicio Nacional de Sanidad y Calidad Agroalimentaria (SENASA 2008, 2013), en septiembre de 2008 se registraban oficialmente 1420 establecimientos de engorde a corral. En junio de 2013, el número se elevó a 1679, con más de 1200000 animales. Según el último informe de SENASA (2008-2013), 
el $69 \%$ de los establecimientos mantuvo una producción menor o igual a 500 animales por ciclo productivo y el 13\% entre 500 y 1000, sosteniendo entre ambas categorías el $24 \%$ del total de las existencias bovinas.

Estos establecimientos podrían no representar una amenaza ambiental dado el bajo número de animales que sostienen. Sin embargo, el gran desarrollo de esta actividad en la Pampa Húmeda, caracterizada por lluvias de $\sim 1000 \mathrm{~mm} /$ año y una amplia red hidrográfica de ríos y arroyos, implica un riesgo ambiental severo sobre los recursos hídricos de la región; esto convierte a la actividad en fuentes de contaminación puntual (García et al. 2013). Este trabajo tiene como objetivo examinar y sintetizar información disponible sobre aspectos involucrados en el actual manejo de los efluentes de feedlots en la provincia de Buenos Aires, destacando los efectos ambientales y poniendo en evidencia debilidades y futuras acciones que podrían implementarse.

\section{EFECTOS SOBRE LOS CUERPOS DE AGUA}

\section{Aguas superficiales}

Las escorrentías que atraviesan y/o se generan en los corrales de engorde conforman el efluente de estas producciones, cuyo volumen dependerá de la duración e intensidad de las precipitaciones, de la pendiente y rugosidad del terreno, y de las características de la capa de residuos orgánicos acumulados sobre la superficie de los suelos (Gilbertson et al. 1980; Miller et al. 2004).

Numerosas investigaciones sobre flujos de agua en corrales de engorde con diferentes ambientes edáficos, y bajo diferentes condiciones de humedad previa, muestran que una alta proporción del agua de lluvia escurre y que una proporción menor infiltra, saturando los primeros centímetros de la capa de estiércol (Miller et al. 2006; Gilley et al. 2008; García et al. 2012). Si bien el espesor, las condiciones de humedad previa y el grado de compactación de la capa orgánica contribuyen a definir la amplitud de los procesos de escorrentía e infiltración, en términos generales la capa orgánica favorece la escorrentía, lo que limita la infiltración a valores característicos de suelos pocos permeables (entre 3 y $6 \mathrm{~mm} / \mathrm{h}$ ) (Maule \& Fostand 2002; García et al. 2012). Por consiguiente, en la Pampa Húmeda, con lluvias de gran intensidad o con períodos lluviosos crónicos que saturan rápidamente la capa orgánica, se genera un volumen importante de escorrentías que es necesario contener o redirigir para evitar que sigan el flujo natural en la cuenca hacia el curso de agua receptor.

Las escorrentías generadas en corrales de engorde presentan concentraciones elevadas de sólidos suspendidos (SS), materia orgánica biodegradable $\left(\mathrm{DBO}_{5}\right)$, nutrientes (N y P) y sales (Tabla 1). Además, contienen constituyentes menores como metales ( $\mathrm{Cu}, \mathrm{Zn} \mathrm{y} \mathrm{Fe})$ y compuestos orgánicos (antibióticos, antiparasitarios, hormonas y otros ionóforos), así como patógenos (Giardia, Escherichia coli) (Herrero \& Gil 2008). Al comparar la composición de las escorrentías con los niveles guías de los parámetros de calidad de agua para la vida acuática, establecidos por reglamentaciones nacionales e internacionales, se pone en evidencia su capacidad contaminante. El fósforo total (PT) en el efluente alcanza una concentración media de $65 \mathrm{mg} / \mathrm{L}$, mientras que un sistema acuático clasificado como mesotrófico mantiene concentraciones que varían entre 20 y 30 g/L(CCME 1999). La concentración

Tabla 1. Características del efluente de lagunas de almacenamiento en un feedlot comercial (Marcos Paz, provincia de Buenos Aires).

${ }^{*}$ Los muestreos fueron efectuados inmediatamente luego de cada lluvia efectiva.

${ }^{* *}$ SS: 1 h (ml/L). DE: desvío estándar. Fuente: Vázquez Pugliese 2013.

Table 1. Effluent characteristics from holding ponds in a commercial feedlot (Marcos Paz, Buenos Aires).

* Samplings were performed immediately after each effective rain.

${ }^{* *}$ SS: 1 h (ml/L). DE: standard deviation. Source: Vázquez Pugliese 2013.

\begin{tabular}{clc}
\hline Variable $^{*}$ & & Media (DE) \\
\hline $\mathrm{N}_{-}-\mathrm{NO}_{3}$ & $\mathrm{mg} / \mathrm{L}$ & $2.49( \pm 2.27)$ \\
$\mathrm{N} \mathrm{NH}_{4}$ & $\mathrm{mg} / \mathrm{L}$ & $126.2( \pm 49.9)$ \\
$\mathrm{PT}$ & $\mathrm{mg} / \mathrm{L}$ & $65.8( \pm 19.15)$ \\
$\mathrm{PRS}$ & $\mathrm{mg} / \mathrm{L}$ & $36.73( \pm 19.59)$ \\
$\mathrm{K}$ & $\mathrm{mg} / \mathrm{L}$ & $1514.4( \pm 375.7)$ \\
$\mathrm{Na}$ & $\mathrm{mg} / \mathrm{L}$ & $459.8( \pm 76.6)$ \\
$\mathrm{Mg}$ & $\mathrm{mg} / \mathrm{L}$ & $59.8( \pm 6.8)$ \\
$\mathrm{Ca}$ & $\mathrm{mg} / \mathrm{L}$ & $208.5( \pm 32.9)$ \\
$\mathrm{DQO}$ & $\mathrm{mg} / \mathrm{L}$ & $8979.5( \pm 2549.6)$ \\
$\mathrm{DBO}$ & $\mathrm{mg} / \mathrm{L}$ & $2161.43( \pm 621.8)$ \\
$\mathrm{SS}$ & $\mathrm{mg} / \mathrm{L}$ & $3.64( \pm 3.18)$ \\
$\mathrm{SST}$ & $\mathrm{mg} / \mathrm{L}$ & $2236.4( \pm 1104.8)$ \\
$\mathrm{CE}$ & $\mathrm{dS} / \mathrm{m}$ & $4.9( \pm 1.57)$ \\
\hline
\end{tabular}




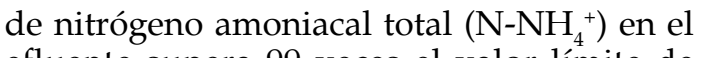
efluente supera 99 veces el valor límite de nitrógeno amoniacal total $(\mathrm{pH}=7.5$ y a 20 ${ }^{\circ} \mathrm{C}$ ) requerido para proteger la vida acuática según las normas canadienses (CCME 1999) y la Ley 24051 de Residuos Peligrosos, como también lo hacen las concentraciones de SS y de $\mathrm{DBO}_{5}$ (Tabla 1). Asimismo, especies microbiológicamente activas como las coliformes totales están presentes en estos efluentes en cantidades que varían entre $10^{5}$ y $10^{6} \mathrm{UFC} / \mathrm{ml}$ (Shouse 2012), superiores a los niveles guías de calidad de agua para riego (100 UFC/100 ml) (CCME 1999), pudiendo causar enfermedades transmitidas por el agua. Estos datos manifiestan la necesidad de tratar este tipo de efluentes para poder descargarlos en un curso de agua de manera sostenida en el tiempo.

Una de las consecuencias de la descarga de estos efluentes en un curso de agua sin un tratamiento apropiado está dada por la disminución del oxígeno disuelto (OD). Los cambios en el OD de un río están íntimamente asociados a procesos de degradación bioquímica, que ocurren como consecuencia de la oxidación de la materia orgánica de los efluentes vertidos (Chapra 1997; USEPA 1997). Frente a una descarga puntual continua de efluentes orgánicos se produce una variación de OD en función de la distancia al punto de vertido (Figura 1). El oxígeno presente en el medio es consumido por los microorganismos heterótrofos, disminuyendo su concentración. La disminución llega a un mínimo, punto crítico (Figura 1), a partir del cual el sistema comienza a recuperarse, la materia orgánica se degrada o sedimenta en el fondo y la población bacteriana disminuye, aumentando nuevamente el OD. Cuando la concentración de OD llega a valores menores a $4 \mathrm{mg} / \mathrm{L}$, nivel guía para la protección de la vida acuática (CCME 1999), puede producirse mortandad de peces y de otros organismos. Por consiguiente, es importante considerar al nivel guía de OD como el mínimo valor a alcanzar frente a una descarga de efluente.

Asimismo, el amoníaco es otro de los gases disueltos que aumenta su concentración con la descarga de estos efluentes, pudiendo generar un impacto severo por su toxicidad para los peces. La susceptibilidad a daños por amoniaco varía entre especies aunque los efectos negativos pueden comenzar a concentraciones tan bajas como $0.01 \mathrm{mg} /$ L. Cuando la contaminación del estiércol provoca la muerte de peces, la concentración de amoníaco es con frecuencia una de las causas principales.

La aceleración del proceso evolutivo de eutrofización natural (eutroficación) es otras de las consecuencias provocadas por del aumento de nutrientes $(\mathrm{N}$ y $\mathrm{P})$ provenientes de degradación de la materia orgánica de estos efluentes (García \& Iorio 2003). Este proceso genera cambios sintomáticos entre los que se destacan: aumento de la biomasa algal, disminución de la diversidad general, alteración de las especies dominantes, aumento de los microorganismos heterótrofos, cambios metabólicos generales, alteración de los ciclos biogeoquímicos, entre otros. Bajo estas características, las sustancias tóxicas provenientes de las cianobacterias potencian los efectos negativos y restringen el uso del agua como recurso.

La magnitud del impacto ambiental no sólo depende de la capacidad contaminante del efluente sino también de las condiciones ambientales del curso receptor. La mayoría de los ríos y arroyos de la provincia de Buenos

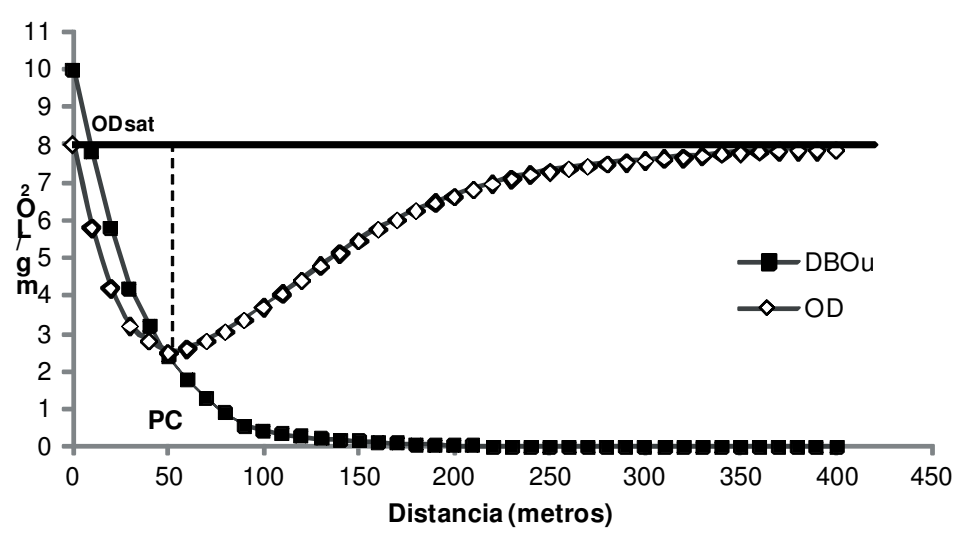

Figura 1. Variación esquemática de las concentraciones de oxígeno disuelto (OD) y demanda bioquímica de oxígeno total (DBOu) aguas abajo del punto de vertido de un efluente orgánico. Fuente: Chapra 1997.

Figure 1. Variation of dissolved oxygen (DO) and total biochemical oxygen demand $(\mathrm{BODu})$ concentrations downstream from the discharge point of an organic effluent. Source: Chapra 1997. 
Aires son de régimen fluvial permanente, con una gran capacidad de diluir y procesar el efluente (capacidad asimilativa), de manera de amortiguar los efectos negativos de los contaminantes, manteniendo su calidad (Cairns 1999). Un establecimiento de engorde a corral con una carga instantánea de 300 animales que descarga las escorrentías en el Arroyo del Medio puede tener muy poco impacto medible, mientras que si las descarga en una laguna o en un pequeño arroyo, el impacto puede ser importante. El riesgo de impacto significativo es mucho menor cuando el caudal es grande, como ocurriría con el Río de la Plata, o está en muy alto flujo (inundación). En estos casos el efecto dilutorio daría cuenta del escaso o nulo impacto medible.

\section{Aguas sub-superficiales}

Las aguas subterráneas son más difíciles de contaminar debido a las reacciones de sorción y descomposición química y biológica que sufre el contaminante al atravesar la zona vadosa. No obstante, cuando ello ocurre es más difícil de recuperar que un curso superficial (i.e., comprende un entorno de alta resistencia pero de muy baja resiliencia). La razón de que esto ocurra se debe, en parte, a la natural ausencia de materia orgánica en el sistema, que determina una baja población de organismos descomponedores nativos. Además, la falta de oxígeno y el ritmo de renovación muy lento dificultan aún más la autodepuración del sistema.

Investigaciones realizadas en corrales de engorde revelan la lixiviación de compuestos altamente contaminantes hacia las aguas subsuperficiales (Maule \& Fonstad 2000; Maisonnave 2002; Andriulo et al. 2003). Así lo manifestaron los estudios realizados por Arnold \& Meister (1999), quienes encontraron elevados niveles de nitrato, amonio, cloruro, nitrógeno orgánico y sólidos disueltos en muestras de agua subsuperficial colectadas de siete feedlots durante un período de seis años en Nueva México. Estos resultados concuerdan con los encontrados por García et al. (2013) tras un monitoreo de tres años del agua freática y los acuíferos subyacentes a un feedlot de la provincia de Buenos Aires construido sobre un suelo argialbol típico cuyo rasgo característico es la presencia de un horizonte iluvial Bt fuertemente textural que reduce el drenaje. Hasta el momento, los resultados no muestran contaminación inorgánica en los acuíferos Puelche y Epipuelche, en tanto que los niveles de contaminantes en el agua freática oscilan con la altura de la napa, superando significativamente los valores obtenidos en aguas subyacentes a campos agrícolas de la zona (control). Es importante destacar que el acuífero Epipuelche se recarga por infiltración directa de las lluvias y es fuente de recarga del acuífero Puelche cuando su potencial agua es mayor. Por lo tanto, la contaminación del agua freática indica un riesgo potencial de contaminación de los acuíferos más profundos.

\section{REGULACIONES SOBRE EL VERTIDO DE EFLUENTES}

El carácter contaminante de los residuos generados por el engorde de ganado vacuno a corral conduce a la necesidad de contar con normativas claras que regulen el manejo y la disposición final de los desechos. La normativa existente a nivel nacional que vincula las actividades con el cuidado del ambiente es la Ley General del Ambiente (Ley 25675). Esta ley no es exclusiva para las actividades ganaderas intensivas y, por consiguiente, carece de pautas específicas. Establece la obligación de realizar un estudio de impacto ambiental aunque no define los aspectos técnicos a relevar. A su vez, existen instrumentos de control a nivel provincial y municipal que no responden a un mismo marco general, dando lugar a una diversificación de los criterios generales que guían el manejo de los residuos.

En la provincia de Buenos Aires, la ley 5965 (de la década del sesenta) establece los principios fundamentales para la protección de las fuentes de provisión de agua y los cursos receptores de agua y la atmósfera. Prohíbe la descarga de efluentes a la atmósfera o a cualquier cuerpo de agua superficial o subterránea que signifique la degradación de su calidad. En su decreto reglamentario 2009/ 60 , se describen los criterios de vuelco, basados en la capacidad asimilativa del curso de agua receptor. Este decreto fue reemplazado por otro (3970/90), de manera tal que generan incertidumbre ya que establecen dos valores de concentración de sustancias flotantes que pueden cambiar el aspecto natural del cuerpo receptor, $50 \mathrm{mg} / \mathrm{L}$ y $150 \mathrm{mg} / \mathrm{L}$.

En el año 1999, en la provincia de Buenos Aires se promulgó la ley 12257, que crea 
el "Código de Aguas" y el ente autárquico "Autoridad del Agua" (ADA), que vela por su cumplimiento y el de las leyes que lo modifiquen. En el código se establece el régimen de protección, conservación y manejo de los recursos hídricos de la provincia de Buenos Aires. Más tarde, la resolución 336/ 2003 (promulgada por ADA) estableció los parámetros de descarga de efluentes líquidos en cuerpos de agua superficial y colectoras cloacales, mar abierto, y absorción por el suelo. La definición de los límites admisibles de estos parámetros presenta ciertas debilidades ya que se establece de manera general para todo tipo de efluentes (inorgánico u orgánico), sin considerar las características específicas de los residuos generados en las diferentes industrias. Este concepto es clave, pues según la especiación química variará el impacto ecológico del vertido. Además, los valores límites se consideran en unidades de concentración y no en masa, es decir, no se tiene en cuenta el caudal de descarga, ni el caudal del río al momento de la descarga. Este aspecto sugiere un desconocimiento del sistema, ya que supone que todos los ríos, arroyos y/o lagunas son iguales y responden de la misma forma. Es importante destacar que en la definición de estos valores no se informa el criterio o la base científica que los determina. Los niveles de descarga en cursos superficiales de agua propuestos no responden a los niveles guías de los parámetros de calidad de agua del cuerpo receptor, y menos aún a su capacidad asimilativa, como lo establece el decreto 2009/60 y su modificación 3970/90, aún vigentes. Sucede algo semejante con los límites admisibles de descarga en suelos, ya que no se conocen los criterios sobre los cuales se establecieron los niveles de vuelco, no se tiene en cuenta la capacidad de adsorción del suelo ni la de absorción por la vegetación.

Si comparamos las reglamentaciones vigentes [ley 5965 y sus decretos, por un lado, y ley 12257 y sus decretos y normativas derivadas (entre ellos la Res. 336/03), por el otro] se pone en evidencia la divergencia de criterios que se establece entre ellas para definir niveles de vuelco. La primera tiene en cuenta la calidad del agua del cuerpo receptor y su capacidad asimilativa. En este caso el nivel de vuelco será determinado aplicando herramientas como modelos para establecer la descarga máxima total diaria implementando un criterio similar al utilizado por la Agencia de Protección Ambiental de Estados Unidos
(USEPA 1997), a partir de un verdadero proceso de análisis de los efectos ambientales locales. Además, esta ley brinda pautas para el diseño de tratamiento. Mientras, la normativa más reciente a través de la Res. 336/03(ADA), si bien dice tener en cuenta la ley 5965, establece valores fijos de límites admisibles de los parámetros de vuelco con los cuales evalúa y no da pautas para el nivel de tratamiento que se espera. Esta incongruencia que se presenta dentro de la propia resolución se traslada a las demás resoluciones de ADA (e.g., la Res. 275/08 hace referencia al régimen de multas). Evidentemente, esta brecha de criterios puede llevar a dictaminar diferentes fallos según se interprete cada caso según la Res. 336/03 (ADA) o bien siguiendo el criterio establecido por el decreto reglamentario 2009/ 60 de la ley 5965.

El resto de la legislación disponible sobre manejo de efluentes y su disposición a nivel nacional y provincial (Buenos Aires) se refiere casi exclusivamente a aquellos de origen industrial. De este modo, la actividad de feedlot queda excluida, por lo que las contradicciones señaladas adquieren una relevancia aun más grande, ya que componen la única forma regulatoria sobre la actividad (de manera indirecta, pero alcanzándola). Por consiguiente, que las normativas no sean claras, ni compatibles deja a los feedlots en una situación muy compleja de operación e involucra un riesgo ambiental potencial muy elevado.

\section{Manejo aCtual de los efluentes}

La realidad económica del país, excesivamente competitiva en esta producción, y los pequeños márgenes de ganancia hacen que los productores no consideren los costos ambientales de su producción. La mayoría de los feedlots argentinos no cuentan con un sistema eficiente para el tratamiento de los efluentes. Partiendo del lugar donde se generan las escorrentías, los corrales de engorde no siempre están ubicados en el lugar más apropiado del paisaje como para evitar el paso de las escorrentías de áreas vecinas, ni están diseñados y mantenidos como para que el agua escurra lo más clara y rápidamente posible. La mayoría de las veces no se presentan sedimentadores o áreas del terreno (canales) diseñadas para esta función. Tampoco se diseña el lugar apropiado para apilar el estiércol que se extrae desde los 
corrales, ni la construcción de las pilas como para favorecer el compostado. Las obras de contención - lagunas- en general no están impermeabilizadas; son construidas sin tener en cuenta los factores generadores del escurrimiento o sin la realización de un estudio previo del régimen hídrico característico de la zona, resultando muchas veces en sistemas con capacidad insuficiente para contener los volúmenes escurridos. Tampoco está asociada a esta práctica la reutilización del efluente o estiércol sólido como fertilizante orgánico en la agricultura. La falta de integración está dada por la desvalorización de este residuo como recurso, que se refleja en la ausencia de lineamientos de las reglamentaciones.

En la región, en general, esta práctica no se planifica desde el comienzo de la actividad, y puede ocurrir que el establecimiento no disponga del terreno suficiente para esparcir el estiércol o el efluente generado. Como consecuencia, se descarga más de lo que se debería de acuerdo a la capacidad física del suelo para el uso agronómico, o bien se descarga en otros espacios (e.g., ríos, arroyos, áreas bajas del terreno). Las multas y suspensiones (totales o parciales) a ciertas prácticas de manejo están obligando al productor a instalar y manejar sistemas de control de la posible contaminación con altos costos, limitando el crecimiento de la actividad.

\section{DESAFÍOS Y OPORTUNIDADES}

Para lograr la sustentabilidad de estas producciones es necesario definir su tamaño en función de la cantidad de residuo generado y de su disposición final. La utilización de los nutrientes remanentes al sistema de engorde a corral como fertilizante orgánico, es una de las posibilidades de destino del efluente tratado. Esta aplicación permite garantizar la máxima utilización de los nutrientes incrementando la producción de cultivos, cerrando todo el circuito. Cuando no se dispone de terreno suficiente para esta práctica, los efluentes pueden reutilizarse en múltiples actividades transformándolos a partir de tecnologías de mayor desarrollo; o bien se descargan, total o parcialmente, en un curso de agua superficial después de un tratamiento que les permita alcanzar los requerimientos de vuelco establecidos en reglamentaciones definidas en forma clara y específica para estas producciones y fundamentadas en el mantenimiento de la calidad de los recursos.

Bajo este marco de análisis, es importante contar con una regulación integral que tenga en cuenta la implementación de programas, más que el cumplimiento de estándares. La regulación debería incluir un plan de manejo de nutrientes (PMN) de manera de regular la descarga en suelos, y además, programas de permisos de descargas en cursos superficiales de agua, que podrían estar acordes a las tecnologías de base, aplicables a nivel nacional, para el tratamiento de los efluentes y a los requisitos de descargas basados en la calidad del curso de agua receptor.

La Figura 2 muestra el esquema operativo utilizado para enmarcar el análisis de los diferentes aspectos involucrados en el manejo de los efluentes de feedlots. El esquema identifica cuatro componentes: Producción (Unidades de Animales UA), Cantidad y Calidad de Escorrentías, Recolección y Tratamiento, y Disposición Final, establecidos a partir de dos criterios técnicos: 1) la elaboración de un Plan de Manejo de Nutrientes (PMN) a partir de la superficie de terreno disponible para ello, y 2) la elaboración de programas de permisos de descargas en cursos de agua superficial, para lo cual habrá que definir un Criterio de Control de Efluente (CCE).

El PMN debería considerar acciones sitioespecíficas, acordes a las prácticas agrícolas propias del lugar, aplicando tecnologías emergentes, económicamente posibles y bajo un marco ambiental seguro (minimizando las pérdidas de nutrientes). Por consiguiente, una vez definido el tamaño del feedlot (en función del terreno disponible para la reutilización del efluente) y el sistema de tratamiento (Efluente 1), es necesario elaborar un plan estratégico de manejo donde se ajusten los factores: dosis, método, momento y frecuencia de aplicación de estiércol en función del rendimiento esperado de un cultivo determinado y la disponibilidad de nutrientes del suelo. El método, el momento y la frecuencia de aplicación del estiércol son factores importantes que darán como resultado mayor absorción, menor pérdida y mayor control de la calidad del agua. Existe evidencia que demuestra que la reutilización de estiércol como fertilizante permite abaratar costos de fertilización, mejorando la calidad del suelo y dándole un destino final controlado, evitando riesgos de contaminación (Sweeten 1998; USEPA 2001; Ciapparelli \& García 2015). 
Los programas de permiso de descargas en aguas superficiales deberían estar sujetos al criterio que se adopte para definir el control de efluentes (CCE), es decir las características del efluente después del tratamiento (Efluente 2, Figura 2) y en consecuencia el tratamiento. Existen distintos criterios: los basados sólo en la tecnología propondrán la mejor tecnología disponible para poder lograr los niveles de vuelco acordes con los niveles guías de calidad de agua, establecidos en términos de masa. Aquellos basados en la tecnología económicamente posible y en la capacidad asimilativa del cuerpo receptor tendrán en cuenta las condiciones ambientales sitioespecíficas y económicamente disponibles. La importancia de estos últimos criterios reside en la posibilidad de definir valores de vertido aceptables para un curso de agua, muy por encima de los valores establecidos en la norma reglamentaria vigente. En consecuencia esto conlleva, por un lado, a hacer frente a épocas de lluvia donde la cantidad de efluente generado supere la capacidad de almacenamiento y reutilización propuesta por la normativa. Por otro lado, permite abaratar costos de tratamiento ya que la tecnología necesaria para la eliminación de concentraciones menores implica los mayores costos.

En Argentina, la ausencia de datos locales (tanto hidrológicos como de los efluentes generados) limita las posibilidades de calcular niveles de vuelco a partir de la capacidad asimilativa de nuestros ríos. La capacidad asimilativa se modela a partir de un cálculo donde se establece la descarga máxima total diaria (Total Maximum Daily Load Prosses) (USEPA 1999), que tendría que ajustarse a la realidad de nuestros sistemas. La ausencia de información es una de las principales causas que conducen a políticas de desarrollo inapropiadas y que promueven la conversión, la sobreexplotación y la destrucción de espacios naturales vitales, así como una menor competitividad y rentabilidad en el sector productivo. Por consiguiente, esta revisión pone en relieve la importancia de contar con datos sobre el funcionamiento de nuestros recursos hídricos así como el fortalecimiento de grupos de investigación que trabajen en este área del conocimiento.

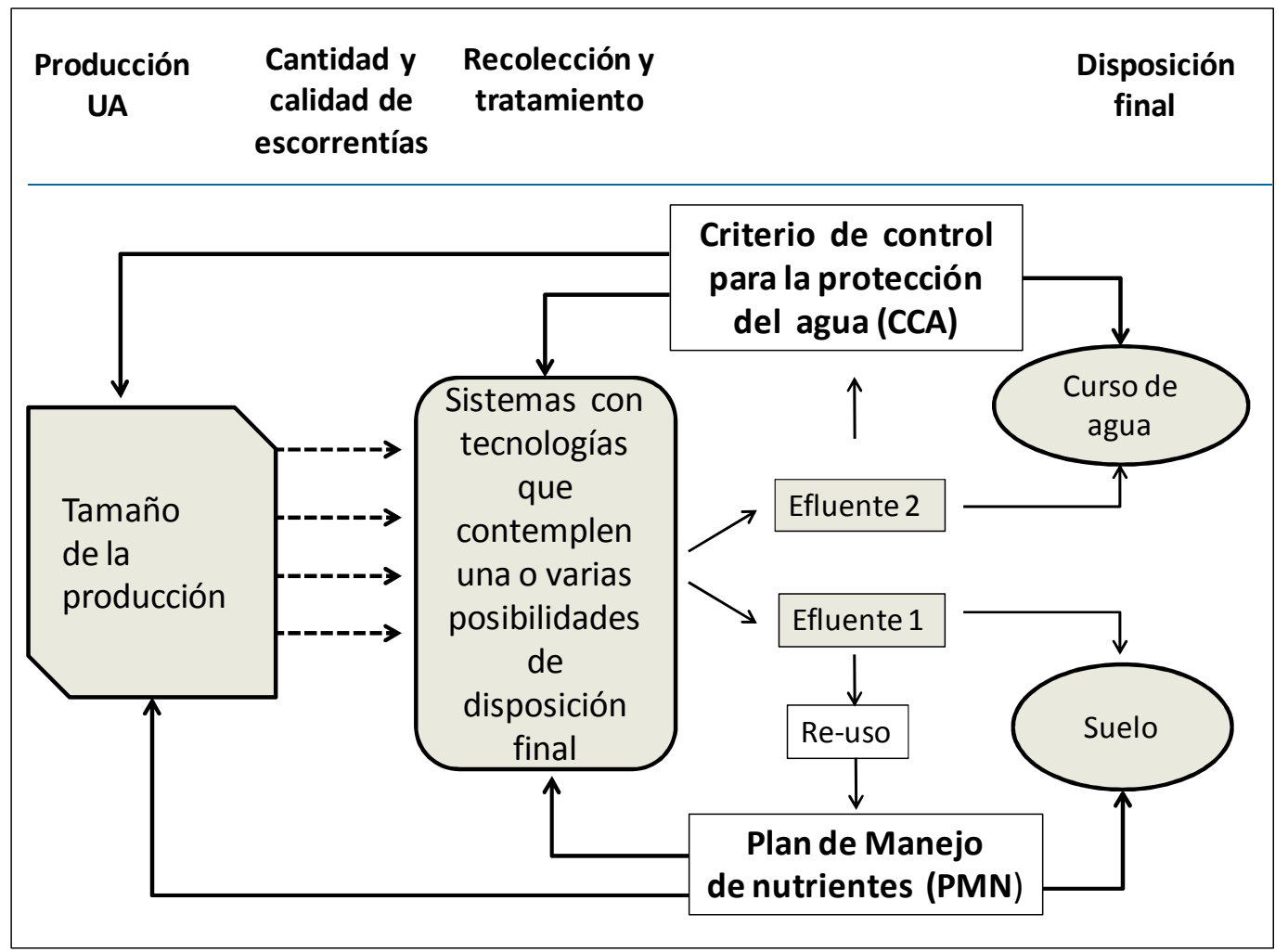

Figura 2. Esquema operativo utilizado para enmarcar el análisis de diferentes aspectos involucrados en el manejo de los efluentes de feedlots.

Figure 2. Operating scheme used to frame the analysis of different aspects involved in feedlot effluent management. 


\section{BIBLIOGRAFÍA}

Andriulo, A; C Sasal; C Améndola \& F Rimatori. 2003. Impacto de un sistema intensivo de producción de carne vacuna sobre algunas propiedades del suelo y del agua. INTA, Argentina. Ria, 32(3):27-56.

ARNold, ST \& EA MEISTER. 1999. Dairy feedlot contributions to ground water contamination: a preliminary study in New Mexico. J. Environ. Health, 62(2):16-19.

CaIrns, JJ. 1999. Assimilative capacity - the key to sustainable use of the planet. Journal of Aquatic Ecosystem Stress and Recovery, 6:259-263.

CCME (Canadian Council of Ministers of the Environment). 1999. Canadian environmental quality guidelines, Canadian Council of Ministers of the Environment, Winnipeg. [Doc. en línea] en: http:// www.ccme.ca/en/resources/canadian_environmental_ quality_guidelines/ index.html. [Consultado: abril de 2015].

Chapra, SC. 1997. Surface Water-Quality Modeling. New York: McGraw-Hill. Pp. 844.

Ciapparelli, I \& AR García. 2015. Use of Manure to Wheat Production in an Argentinean Hapludoll soil. J. Pollut. Eff. Cont., 3(1):131.

García, AR; SN Fleite; D Vázquez Pugliese \& AF de IORIO. 2013. Feedlots and pollution-A growing threat to water resources of agro-production zone in Argentina. Environmental Science \& Technology, 47(21): 11932-11933.

GARCíA, AR \& AF DE IORIO. 2003. Phosphorus distribution in sediments of Morales Stream (tributary of the Matanza-Riachuelo River, Argentina). The influence of organic point source contamination. Hydrobiología, 492:129 -138.

García, AR; R Maisonnave; M Massobrio \& AF de Iorio. 2012. Field-scale evaluation of water fluxes and manure solution leaching in feedlot pen soils. J. Environ. Qual., 41:1591-1599.

Gilbertson, CB; RN Clark \& NP Swanson. 1980. Runoff control for livestock feedlots. A state of the art. Agricultural information bulletin 441, USDA, Agricultural Research Service, Washington, DC. Pp. 19.

Gilley, JE; ED Berry; RA Eigenberg; DB Marx \& BLWOODBURY. 2008. Spatial variations in nutrient and microbial transport from feedlot surfaces. Trans ASABE, 51(2):675-684.

HerRero, MA \& S GiL. 2008. Consideraciones ambientales de la intensificación en producción animal. Ecol. Austral, 18(3):273-289.

Maisonnave, R. 2002. Consecuencias ambientales de la producción de carne en sistemas intensivos. Tesis para optar al título de Master en Ciencias Ambientales. Biblioteca de la Facultad De Ciencias Exactas y Naturales. UBA. Argentina.

Maule, CP \& TA Fonstad. 2002. Solute migration and moisture flux beneath cattle feedlot pens. Transactions of the American Society of Agricultural Engineers, 45:73-81.

Mazzone, J; P Dillion \& P Pavelic. 1992. A review of the impact of feedlots on groundwater quality. Center For Groundwater Studies. Report n ${ }^{\circ}$ 43. Pp. 25.

Miller, JJ; B Beasley \& CS Olson. 2006. Bedding and within-pen location effects on feedlot pen runoff quality using a rainfall simulator. J. Environ. Qual., 35(2):505-515.

Miller, Jj; BP Handerek; BW Beasley; ECS Olson; LJ Yanke; ET AL. 2004. Quantity and quality of runoff from a beef cattle feedlot in Southern Alberta. J. Environ Qual, 33(3): 1088-1097.

ROBERT, S \& F SANTANGelo. 2009. Estructura del feedlot en Argentina - Nivel de asociación entre la producción bovina a corral y los titulares de faena. IPCVA-CEPAL.

Senasa (Servicio Nac. de Sanidad y Calidad Agroalimentaria). 2008. Indicadores Ganadería Bovina. Información del Sistema Integrado de Gestión para la Sanidad Animal. [Doc. en línea] en: http:/ / www.senasa.gov.ar/ indicadores.php?d=1_indicadores_Ganaderia_ Bovina\&in=1 [Consultado: abril de 2015].

Senasa (Servicio Nac.de Sanidad y Calidad Agroalimentaria). 2013. Indicadores Ganadería Bovina. Información del Sistema Integrado de Gestión para la Sanidad Animal. [Doc. en línea] en: http:/ / www.senasa.gov.ar/ indicadores.php?d=1_Indicadores_Ganaderia_ Bovina\&in=1 [Consultado: abril de 2015].

SHouse, S. 2012. Small open beef feedlots in Iowa, a producer guide. Iowa State University. [Doc. en línea] en: http: //www.agronext.iastate.edu/immag/info/ PM3018 openbeeffeedlots. pdf [Consultado: abril de 2015].

Sweeten, JM. 1998. Cattle feedlot manure and waste management practices. Pp. 125-156 en: Hatfield, JL \& BA Stewart (eds.). Animal waste utilization: effective use of manure as a soil resource. Ann Arbor Press, Chelsea, MI.

UsePa (US Environmental Protection Agency). 1997. Technical Guidance Manual for Performing Wasteload Allocations, Book II: Streams and Rivers Part 1: Biochemical Oxygen Demand/Dissolved Oxygen and Nutrients/Eutrophication. Washington DC. EPA 823B-97-0020. Pp. 258.

USEPA (US Environmental Protection Agency). 1999. Draft Guidance for water Quality-based Decisions: The TMDL Process (Second Edition). Washington DC. EPA 841-D-99-001. Pp. 107.

USEPA (US Environmental Protection Agency). 2001. Development document for the proposed revisions to the national pollutant discharge elimination system regulation and the effluent guidelines for concentrated animal feeding operations. Washington DC. EPA 821R-01-003. Pp. 767.

VÁzquez Pugliese, DE 2013. Cantidad y calidad química de las escorrentías en un sistema de engorde a corral (feedlot). Trabajo de Intensificación para optar al título de Ingeniera Agrónoma. Director: García, AR. Biblioteca de la Facultad de Agronomía. UBA. Argentina. 